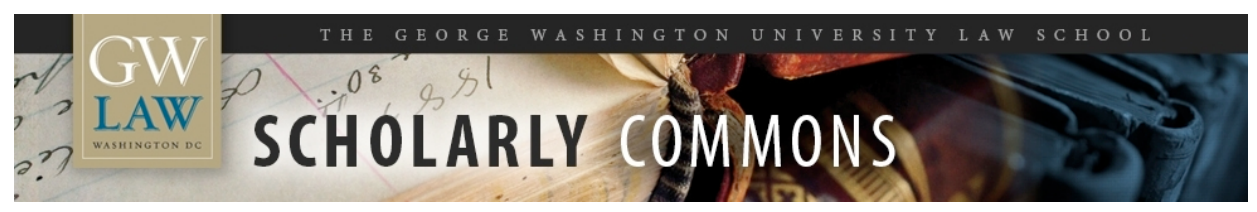

\title{
Child Custody Outcomes in Cases Involving Parental Alienation and Abuse Allegations
}

Joan S. Meier

George Washington University Law School, jmeier@law.gwu.edu

\section{Sean Dickson}

Chris O'Sullivan

Leora Rosen

Jeffrey Hayes

Follow this and additional works at: https://scholarship.law.gwu.edu/faculty_publications

Part of the Law Commons

\section{Recommended Citation}

Meier, Joan S. and Dickson, Sean and O'Sullivan, Chris and Rosen, Leora and Hayes, Jeffrey, Child Custody Outcomes in Cases Involving Parental Alienation and Abuse Allegations (2019). GWU Law School Public Law Research Paper No. 2019-56; GWU Legal Studies Research Paper No. 2019-56. Available at SSRN: https://ssrn.com/abstract=3448062 or http://dx.doi.org/10.2139/ssrn.3448062

This Article is brought to you for free and open access by the Faculty Scholarship at Scholarly Commons. It has been accepted for inclusion in GW Law Faculty Publications \& Other Works by an authorized administrator of Scholarly Commons. For more information, please contact spagel@law.gwu.edu. 
The author(s) shown below used Federal funds provided by the U.S. Department of Justice, and prepared the following final report:

Title: Child Custody Outcomes in Cases Involving Parental Alienation and Abuse Allegations

Principal Author and Principal Investigator: Professor Joan S. Meier, Esq., George Washington University Law School, 202-994-2278, imeier@law.gwu.edu

With

Co-authors, Study Consultants and Quantitative Analysts: Sean Dickson, JD, MPh, Jeffrey Hayes, PhD, Leora Rosen, PhD, Chris O'Sullivan, PhD

Award No.: NIJ-2014-MU-CX-0859 (January 1, 2015 - June 30, 2019) 
Opinions or points of view expressed are those of the authors and do not necessarily reflect the official position or policies of the U.S. Department of Justice or the George Washington University Law School. 


\begin{abstract}
Arguably the most troubling aspect of justice system response to intimate partner violence is custody courts' failure to protect children when mothers allege the father is abusive. Family courts' errors in assessing adult and child abuse, and punitive responses to abuse allegations, have been widely documented.

A significant contributor to these errors is the pseudo-scientific theory of parental alienation (PA). Originally termed parental alienation syndrome (PAS), the theory suggests that when mothers allege that a child is not safe with the father, they are doing so illegitimately, to alienate the child from the father. PA labeling often results in dismissal of women's and children's reports of abuse, and sometimes trumps even expert child abuse evaluations. PAS was explicitly based on negative stereotypes of mothers and has been widely discredited. However, the term parental alienation is still widely used in ways that are virtually identical to PAS. However, because PA is nominally gender neutral (and not called a scientific syndrome), it continues to have substantial credibility in court.
\end{abstract}

The first goal of this project was to ascertain whether empirical evidence indicates that parental alienation, like PAS, is gender-biased in practice and outcome.

Second, the study sought to explore outcomes in custody/abuse litigation by gender and by differing types of abuse. Analysis of over 2000 court opinions confirms that courts are skeptical of mothers' claims of abuse by fathers; this skepticism is greatest when mothers claim child abuse. The findings also confirm that fathers' cross-claims of parental alienation increase (virtually doubling) courts' rejection of these claims, and mothers' losses of custody to the father accused of abuse. In comparing court responses when fathers accuse mothers of abuse, a significant gender difference is identified. Finally, the findings indicate that where Guardians Ad Litem or custody evaluators are appointed, outcomes show an intensification of courts' skepticism toward mothers' (but not fathers') claims, and custody removals from mothers (but not fathers).

The study relies solely on electronically available published opinions in child custody cases. It has produced an invaluable database identifying 15 years of published cases involving alienation, abuse and custody, while coding parties' claims and defenses, outcomes, and other key factors by gender and parental status. 


\section{FINAL SUMMARY OVERVIEW OF FAMILY COURT OUTCOMES STUDY, Grant 2014-MU-CX-0859}

In custody disputes across the country, protective parents and domestic violence professionals have long asserted that family courts frequently deny true claims of adult partner or child abuse and instead punish protective parents who seek to protect children from a dangerous other parent. The "Child Custody Outcomes in Cases Involving Parental Alienation and Abuse Allegations Study" ("FCO Outcomes Study" or "Study") aimed to gather data on how family courts across the United States are deciding child custody cases when parents accuse each other of abuse and/or parental alienation. It seeks to shed empirical light on a polarized debate between professionals involved in family court and the domestic violence field, as well as litigants on both sides.

A significant part of the debate revolves around the label of "alienation" which is frequently used by professionals and accused parents, against a parent reporting abuse. ${ }^{1}$ Anecdotal reports indicate that claims of child abuse are even more problematic in court, and that many protective parents (usually mothers) alleging child abuse are losing custody to the allegedly abusive parent. Reports of severe damage to children forced by courts to be with fathers their protective parents claimed were harmful have been growing. ${ }^{2}$ These claims have gained little

\footnotetext{
${ }^{1}$ See, e.g., Dalton, Carbon \& Olesen, High Conflict Divorce, Violence and Abuse: Implications for Custody and Visitation Decisions, Juv. \& Fam. Ct. Journal 11, 23, 29 (Fall 2003). Parental alienation (or "alienation"), while lacking any universal definition, at its essence, is the theory that when a mother and/or child seek to restrict a father's access to the child, their claims of dangerousness or harm are not true, but due to the mother's anger or hostility, or pathology. Alienation is also used, to a lesser extent, by mothers against fathers.

${ }^{2}$ Joyanna Silberg et al, Crisis in Family Court: Lessons from Turned-Around Cases, Final Report to the Office on Violence against Women, Dep't of Justice 37 (Sept. 30, 2013), http://www.protectiveparents.com/crisis-fam-court-lessons-turned-around-cases.pdf; Center for Judicial Excellence, US Divorce Child Homicide Data, http://centerforjudicialexcellence.org/cje-projects-initiatives/child-murder-data
} 
traction among family court professionals and researchers, who sometimes assert that domestic violence professionals are too credulous, many of mothers' abuse clams are in fact false, and abuse experts/advocates don't appreciate that parental alienation is real, and harmful to children. ${ }^{3}$

\section{Purpose}

The purpose of the FCO Study is to bring neutral empirical data to bear on this controversy: Whether and to what extent it is true that courts are disbelieving abuse claims and removing custody from parents claiming abuse, whether and to what extent gender impacts these findings, and how cross-claims of parental alienation affect courts' treatment of mothers' and fathers' abuse claims. Specifically, the Study sought to produce data on (i) the rates at which courts credit (believe) different types of abuse allegations raised by either parent against the other; (ii) the rates at which parents win/lose the case, or win/lose custody when alleging any type of abuse against the other parent; (iii) the impact of alienation claims/defenses on (i) and (ii) above; and (iv) the impact of gender on (i), (ii), and (iii) above: that is, do rates of crediting of abuse, wins, or custody losses vary when it is a father alleging a mother's abuse, as compared to a mother alleging a father's abuse?

Overall, the Study sought to produce empirical evidence to determine whether or not the contentions of survivors and the abuse professionals who work with them are supported by the data, and if not, to identify any specific areas-- by state or topic - where there still may be troubling or concerning findings.

\footnotetext{
${ }^{3}$ See, e.g., Leslie Drozd and Nancy Olesen, Abuse and Alienation are Each Real: A Response to a Critique by Joan Meier, J. Child Custody 7:4, 253-265 (2010).
} 


\section{Project Design and Methods}

Previous smaller studies have examined outcomes within particular jurisdictions. ${ }^{4}$ The current Study was designed to provide a national overview to assess whether the problems identified in prior localized research are systemic and pervasive. Because there are thousands of custody courts across the country, the only way to gather national data on family court outcomes was to examine judicial opinions posted online. Fortunately, by 2015 , most appellate court opinions were available online, and, as we learned, so were a surprising number of trial court opinions. The search for published opinions covered the 10 -year period from January 1, 2005 through December 31, 2014.

To develop the search and collect the opinions, the Coders and PI reviewed states' differing laws and language to ensure the search did not miss relevant cases. Different search engines and databases were explored and compared, and different search strings were tested. Ultimately, a search string of over 10 lines of search terms was constructed and applied; the LEXIS search netted over 15,000 potentially relevant cases. From these, two Coders triaged out cases that did not pertain to private custody litigation (e.g., cases brought by state agencies), cases involving same sex parents, state-initiated cases, etc. ${ }^{5}$ Ultimately the complete dataset consisted of 4338 cases.

Although the dataset is broad, including cases addressing visitation, joint custody, relocations and other matters, we decided the best way to manage the

\footnotetext{
${ }^{4}$ See Joan Zorza and Leora Rosen, Guest Editors' Introduction, VIOLENCE AGAINST WOMEN $11: 8,983-990$ (Aug. 2005) (summarizing and contextualizing a series of empirical studies in various regions of custody and visitation outcomes where domestic violence is alleged). ${ }^{5}$ See Coding Manual at 3, describing categories that were excluded from the study.
} 
complexity of the dataset would be to start by limiting our focus to three core outcomes (crediting of abuse, custody outcomes, and wins (i.e, which parent won the case, regardless of the requests involved)). We also wanted to start by analyzing only the cleanest, most paradigmatic cases involving abuse and alienation claims, i.e., where one parent accuses the other of abuse or alienation. We therefore excluded from the first set of analyses cases with "third party" victims (e.g., a new or old partner), "mutual abuse" cases, "non-specific" 6 abuse claims, and "AKA"7 claims. This reduced, cleaner "analytic dataset" consists of 2351 cases.

After completing the analyses of the analytic dataset, we then constructed an expanded dataset consisting of all cases containing abuse (intrafamilial and extrafamilial) claims, the "all abuse" dataset, which consists of 2794 cases. While this dataset rolls in cases where a parent is accused of abusing an outside individual (i.e., not in the family at issue in the litigation), it continues to exclude all cases in which both parents accused the other of abuse ("mutual abuse").

Important caveat: Since our "data" consists of judicial opinions, which sometimes fail to specify all allegations by each party, it is likely that some of the 3669 "non-alienation" cases included alienation claims which were not deemed significant enough for the court to mention; the same is likely true with regard to abuse in the 357 opinions we coded as "non-abuse" (or "pure alienation"). It is

\footnotetext{
${ }^{6}$ This code was used when it was not possible to identify whether the abuse alleged was domestic violence, child physical or sexual abuse, or mixed forms.

${ }^{7}$ Although the study focuses on cases with abuse or alienation claims, it does include opinions which described a parent's negative behavior in a manner similar enough to an alienation analysis to be coded as "AKA" ("also known as") cases.
} 
likely that if a court does not mention it in the opinion, the factor played little role in the outcome.

Coders analyzed each opinion and coded 45 items (most with multiple suboptions), such as which parent started out with physical possession of the children, whether either parent alleged alienation or abuse, whether the court credited the abuse or alienation claims, and what the court ordered. They also coded for the presence and opinions of custody evaluators or Guardian Ad Litems, for evidence of corroboration of abuse claims, and many other items. Definitions of coded items are all contained in the Coding Manual. See DOCUMENTATION Appendix B.

\section{Data Analysis}

Once the coding process was complete, the spreadsheets of coded data were transmitted to the statistical consultant who entered them into Stata for quantitative analysis. The PI and consultant Dickson developed analyses for the statistical consultant to complete, reviewed the output, and, through numerous iterations, refined, corrected, and amplified on the particular analyses. New codes were created by the statistician in order to perform these analyses. All codes used in the quantitative analyses conducted are described and defined in the separately submitted Codebook, which indicates inclusions, exclusions and newly created variables for the quantitative analyses. See DOCUMENTATION Appendix C.

In addition to running frequencies and simple correlations between factors and outcomes, logistic regression was used (primarily with the All Abuse dataset) to control for factors that may affect key outcomes, such as differences between trial court and appellate court opinions; differences among states; and the role of gender in custody switches when various forms of abuse or alienation were claimed. 
While the majority (84\%) of cases in the dataset are appeals, hundreds of trial court opinions are also included. The regression analyses indicate, not surprisingly, that parents who lost custody are over-represented in appeals - i.e, the frequency at which custody switches occur is lower (for both genders) among trial court opinions. However, the impact of gender on outcomes is the same among cases that were appealed and those that were not.

\section{Findings}

Cases were coded for partner abuse (DV), child physical abuse (CA) and child sexual abuse (CSA), as well as mixed forms of abuse, i.e., DV + CA or CSA (DVCh) and CA + CSA (CACSA). Altogether, these five categories constitute the coded abuse types. In addition, two primary outcomes were analyzed: Custody switches, in which one parent started with primary custody, and the other parent was awarded primary or full custody by the court; and win rates, where winning captured the parent who "substantially won," i.e., received all or part of their own custody/visitation request, or defeated the other parent's request.

DOCUMENTATION Appendix B (Coding Manual) at 7. For purposes of this report, we focus primarily on crediting of abuse and custody switches. Win rates will be discussed in future publications where there is greater opportunity to contextualize.

The following findings are summarized below:

\section{Analytic Dataset (only intrafamilial abuse and alienation):}

(1) What happens when mothers report fathers' intrafamilial abuse to family court (where there is no alienation defense)?

i. Rates of courts' crediting abuse claims

ii. Rates of custody losses 
(2) What happens when mothers report fathers' intrafamilial abuse to family court, and fathers cross-claim alienation ("PARADIGM" CASES)? Comparison to AKA cases

(3) Selected Reverse-Gender Comparisons of the above

\section{All Abuse Dataset (all cases with claims of abuse by a parent, including extrafamilial victims)}

(4) What happens when either parent reports abusive conduct by the other parent - including alienation, "aka" cases, and non-alienation cases

i. Rates of crediting of abuse (by type)(both genders)

ii. Rates of custody losses (both genders)

iii. Presence of corroboration, GALs, custody evaluators

The following text reports our findings for the above four categories.

\section{ANALYTIC DATASET (intrafamilial abuse only)}

\section{(1) ABUSE CASES - No Alienation Cross-claim}

This portion of the dataset contains 1946 cases in which abuse was alleged by a mother, but alienation was not alleged by the father. ${ }^{8}$

\section{A. CREDITING OF ABUSE}

Rates at which courts credited Mothers' claims of Fathers' abuse:

\begin{tabular}{ll} 
Domestic violence (DV) & 9 \\
Child physical abuse (CPA): & $45 \%(517 / 1137)$ \\
Child sexual abuse (CSA): & $27 \%(73 / 268)$ \\
Mixed DV with CA or CSA (DVCh): & $15 \%(29 / 200)$ \\
\hline
\end{tabular}

${ }^{8}$ The study contains data on reverse-gender cases, but the numbers are very small because it is relatively rare that fathers have physical possession of the children when the case begins. Selected gender comparisons are made below.

${ }_{9}^{9}$ The categories "domestic violence," "child physical abuse" and "child sexual abuse" include only cases where that was the sole type of abuse claimed. Where different types of abuse were alleged, they are captured in the "mixed" categories (DVCh or CACSA). When coding whether abuse claims were credited, coders coded mixed abuse cases as "credited" if one or both of the types of abuse was credited. 
Mixed CA \& CSA (CACSA):

Overall:
$13 \%(5 / 39)$

$41 \%(789 / 1946)$

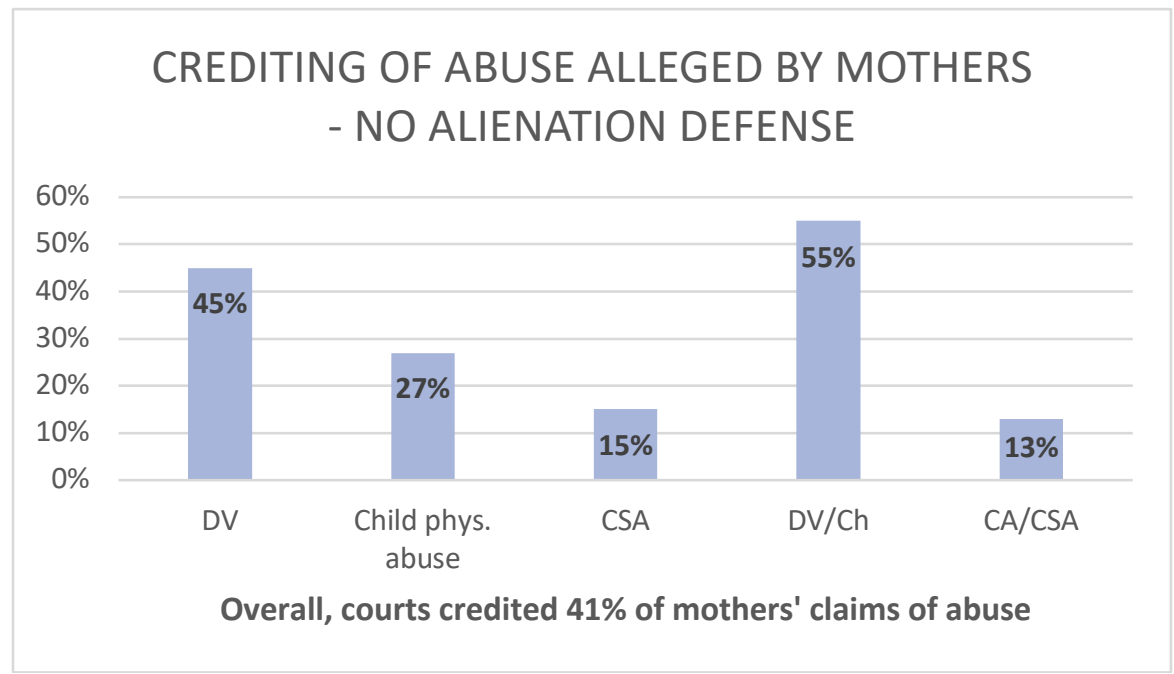

Commentary: Several conclusions can be drawn from these data: First, looking at mothers' claims of abuse, generally, less than half (41\%) of any type of abuse claims are credited. This is a low rate of crediting overall. Moreover, mothers' claims of child abuse are credited even less often than their claims of partner abuse. The odds of a court crediting a child physical abuse claim are 2.23 times lower than the odds of its crediting a domestic violence claim (CI 1.66-2.99). Overall, child sexual abuse is very rarely accepted by courts (15\%). Research indicates that child sexual abuse claims in custody litigation have been found valid at far higher rates. ${ }^{10}$

These findings support protective parents' complaints that courts are not protecting at-risk children from future abuse. The data also refute assertions that women frequently succeed in falsely claiming abuse in court; on the contrary, the data indicate that women's reports of even intimate partner violence are disbelieved more often than not. While this study does not determine the accuracy of courts' beliefs or disbelief in mothers' abuse claims, other research can be brought to bear on that question. (This issue will be addressed in future publications).

\section{B. CUSTODY LOSSES - no alienation defense}

Focusing on cases where it was determined that mothers started with possession of the children, and alleged some type of abuse by the father, the data show mothers

\footnotetext{
${ }^{10}$ Objective outside research has concluded that child sexual abuse claims made in custody litigation are likely valid more than half the time. See Kathleen Colbourn Faller, The Parental Alienation Syndrome: What is it and What Data Support it? Child Maltreatment 3:2 100, 107 (1998) (describing variety of studies finding that $50-72 \%$ of child sexual abuse claims are likely valid).
} 
losing custody in $26 \%(284 / 1111)$ of cases. Broken down by type of abuse alleged $^{11}$ :

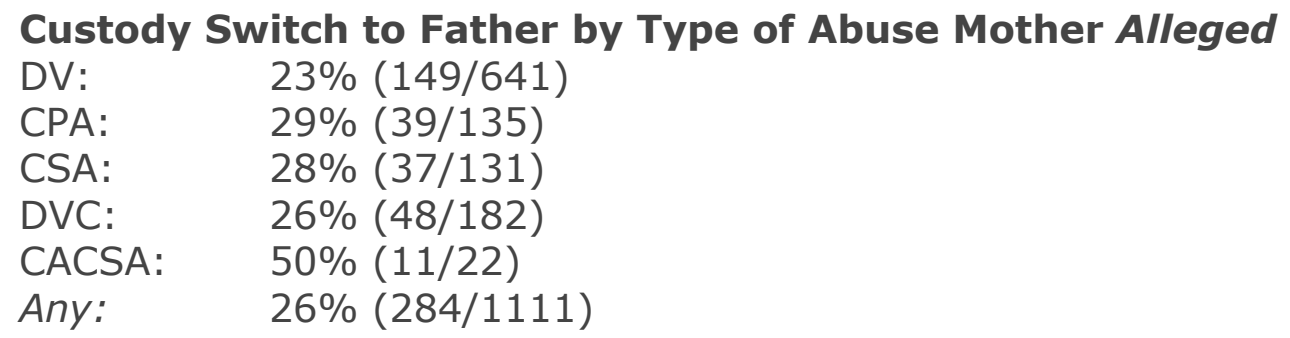

Remarkably, $14 \%(63 / 443)$ of mothers lost custody even when the court credited the father's abuse:

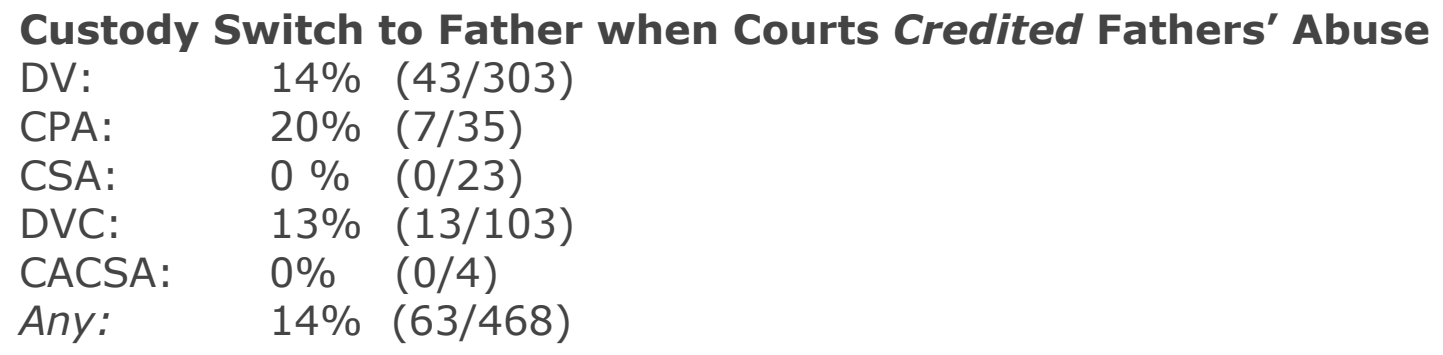

One interesting finding: When courts believe a father had sexually abused his child, they do not switch custody from the mother to the father. However, when they believe the father committed child physical abuse or intimate partner violence, they do switch custody to him approximately 1.4 out of every 10 times. ${ }^{12}$

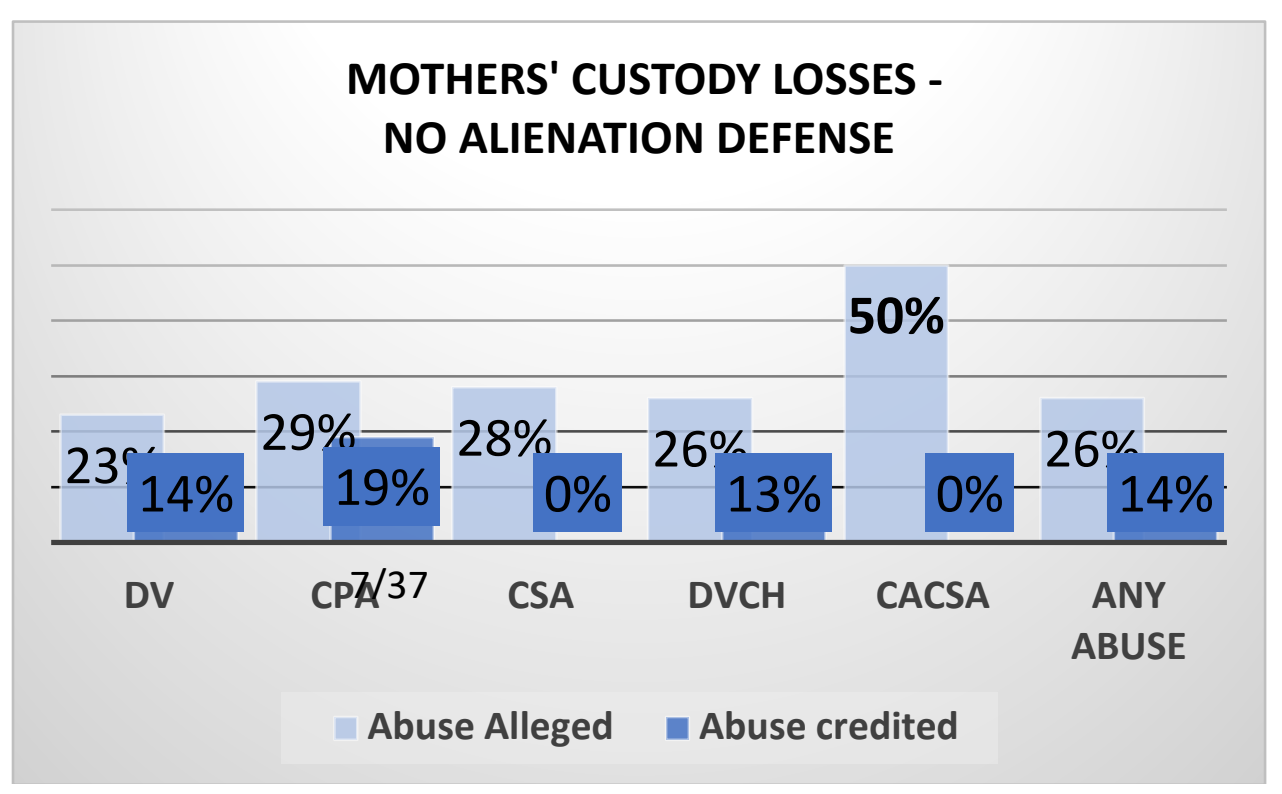

11 "Alleged" means the abuse claim may or may not have been credited.

12 Odds ratios are included herein only when statistically significant. 
Commentary: These data powerfully affirm the reports from the field, that women who allege abuse - particularly child abuse - by a father are at significant risk (over 1 in 4 ) of losing custody to the alleged abuser. (Importantly, this rate applies even in cases where the fathers appear not to have claimed alienation to defeat the abuse claim.) Even when courts find that fathers have abused the children or the mother, they award them custody $14 \%$ of the time. In cases with credited child physical abuse claims, fathers win custody $19 \%$ of the time.

It is also notable that when mothers report mixed types of child abuse (sexual and physical) their custody losses skyrocket (from under 30\% (39/135) up to $50 \%)(11 / 22)$. In effect, mothers have 2.5 times the odds of losing custody when alleging both forms of child abuse than when they allege child sexual abuse alone. ${ }^{13}$ This finding diverges from the pilot study finding of a "child sexual abuse" penalty. ${ }^{14}$ The pilot study, however, did not differentiate between cases where multiple types of abuse were - and those where only one type of abuse was alleged. Therefore the pilot data analysis may may have masked what this study suggests -that it is the combination of child physical and sexual abuse claims that creates a notable "penalty" against mothers.

\section{(2) PARADIGM CASES: Mother alleges abuse; Father claims alienation}

\section{A. CREDiting OF ABUSE}

There were 669 cases in which one parent made an alienation ${ }^{15}$ claim against the other. In 312 of these there were cross-abuse-and-alienation claims. Two hundred and twenty two (222) of these met our definition of paradigmatic cases: mothers accused fathers of abuse and fathers accused mothers of alienation. ${ }^{16}$ In these paradigm cases, mothers' abuse claims were credited at

\footnotetext{
13 This finding is significant at the $P<.05$ level (CI $1.01-6.36$ ).

${ }^{14}$ See Joan S. Meier and Sean Dickson, Mapping Gender: Shedding Empirical Light on Family Courts' Treatment of Cases Involving Abuse and Alienation, $35 \mathrm{~J}$. Law \& Inequality 311,329 (2017)(finding that mothers were 5.3 times more likely to lose custody if they alleged the father sexually abused their child than if they alleged he abused themselves). ${ }^{15}$ We conservatively only coded cases as alienation cases if the court used that word. When courts used similar analyses but different language, cases were coded as a.k.a. ("AKA") cases. AKA cases included in the study were limited to those in which courts expressly found one parent committed such conduct, not those in which it was claimed but not found by the court. While we do not include the AKA cases in our alienation analyses because the AKA cases are limited to credited cases, some limited observations about AKA cases can be made. See pp. 14-15, infra. These cases are also ripe for secondary analyses.

${ }^{16}$ The small number of paradigmatic cases (222) - and of cases with explicit alienation claims by either parent (669) in the entire dataset - is surprising to the researchers, and warrants discussion in future publications. There were also 304 pure AKA cases (and
} 
even lower rates than in the cases discussed above (when the father made no alienation claim):

\section{Rates at which Courts Credited Mothers' Abuse Claims when Fathers Claimed Alienation, by type of abuse:}

$\begin{array}{ll}\text { DV: } & 37 \%(28 / 76) \\ \text { CPA: } & 18 \%(4 / 22) \\ \text { CSA: } & 2 \%(1 / 51) \\ \text { DVCh: } & 31 \%(17 / 55) \\ \text { CACSA: } & 5 \%(1 / 18)\end{array}$

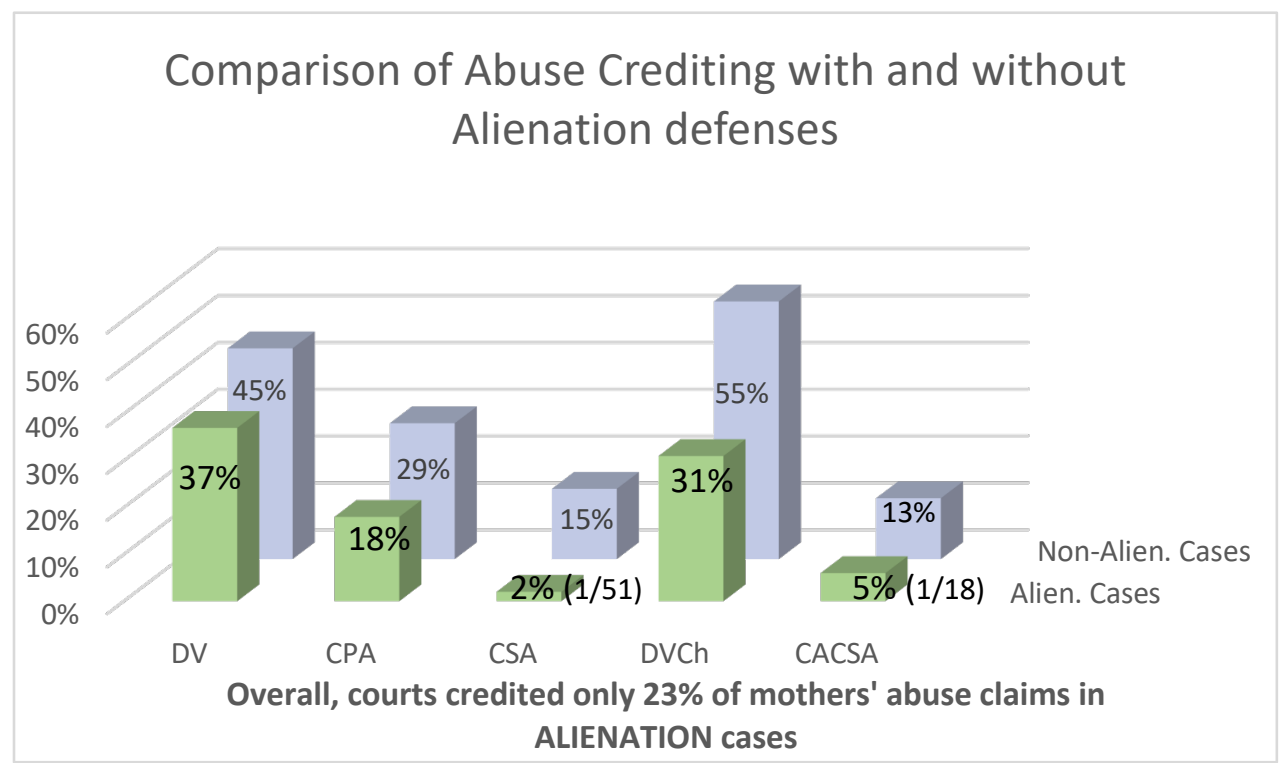

The comparison of rates of crediting of abuse claims when fathers cross-claim alienation to the rate of crediting abuse claims when the father does not claim alienation can be seen in the chart above. These data indicate that

- When Fathers cross-claim alienation, courts are more than twice as likely to disbelieve Mothers' claims of (any) abuse than if fathers made no alienation claim; and

- When Fathers cross-claim alienation, courts are almost 4 (3.9) times more likely to disbelieve Mothers' claims of child abuse than if fathers made no alienation claim.

Commentary: This comparison shows that courts are significantly less likely to credit abuse claims when fathers invoke parental alienation. Among these cases, there is also an even greater drop in the crediting of child abuse than in

another 43 which also contained explicit alienation claims, and were therefore included in the alienation analyses). 
the non-alienation cases: Rates of crediting of child abuse in this population are so low as to be approaching zero. In short, these correlations show that fathers' alienation claims are remarkably effective in undermining (discrediting) mothers' allegations of child abuse. When a father claims a mother is alienating the children from him, a mother's abuse claim is 2.3 times less likely to be credited than when he doesn't.

Given that parental alienation syndrome ("PAS") was created specifically as a rationale for rejecting child sexual abuse claims, it is perhaps not surprising that alienation theory continues to be particularly powerful in application to precisely those cases. Current proponents of the concept of alienation, however, have asserted that it is different from PAS and should not be used in the same way. ${ }^{17}$ These data make clear that the operation of the theory in court has not changed: Neither courts nor professionals who inform the courts seem to have ${ }^{18}$ received that message.

The impact of courts' extreme skepticism of child abuse claims by mothers is seen in the next section findings in regard to mothers' custody losses.

\section{B. CUSTODY LOSSES ${ }^{19}$}

There were 163 cases in which mothers had physical possession of the children at the outset of the litigation and raised abuse claims in court, and fathers alleged mothers were alienating. Similar to the above data on the impact of alienation claims on courts' rates of crediting of abuse, fathers' alienation crossclaims significantly increase the rate of courts' removals of custody from mothers.

\section{Mothers' Custody Losses when Father Claims Alienation by Type of Abuse Alleged by Mother \\ DV: $\quad 35 \%(20 / 57)$ \\ CPA: $\quad 59 \%(10 / 17)$ \\ CSA: $\quad 54 \%(19 / 35)$ \\ DVCh: $\quad 58 \%(25 / 43)$ \\ CACSA: $\quad 64 \%(7 / 11)$ \\ Any: $\quad 50 \%(81 / 163)$}

\footnotetext{
${ }^{17}$ See, e.g., Joan B. Kelly \& Janet R. Johnston, The Alienated Child: A Reformulation of Parental Alienation Syndrome, 39 Fam. Ct. Rev. 249, 251 (2004).

${ }^{18}$ Not only judges but GALs and evaluators contribute to this pattern: The findings in section (4) below indicate that the participation of GALs or evaluators - frequent proponents of the alienation label - reduce courts' crediting of child abuse claims and increase mothers' losses of custody.

${ }^{19}$ See n. 10, supra.
} 
The following chart compares rates at which mothers lose custody in cases with and without an alienation claim by the father:

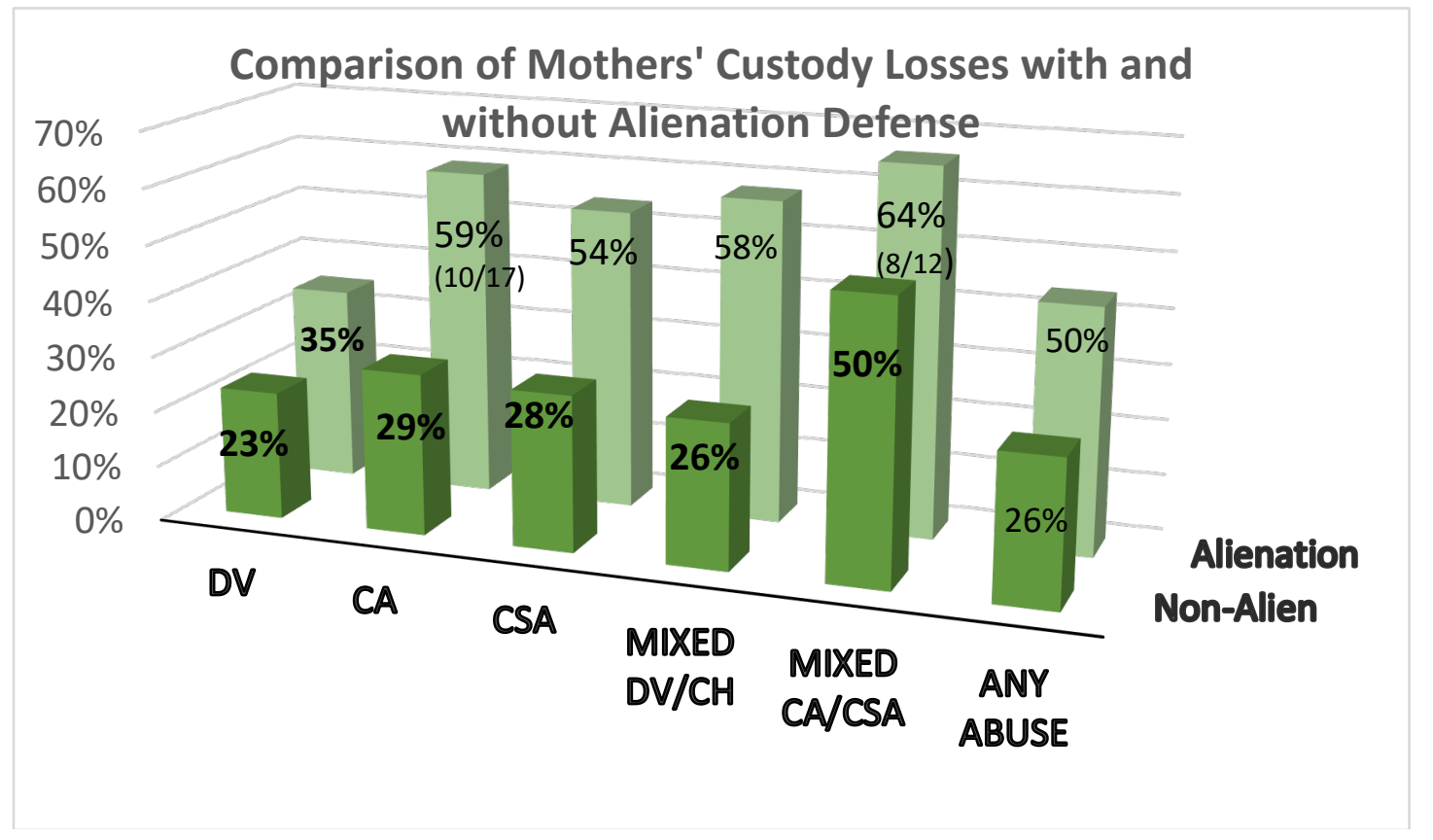

As the chart indicates, when fathers claim alienation, the rate at which mothers lose custody shoots up from over $25 \%$ to over $50 \%$. That is, fathers' alienation claims roughly double mothers' rates of losing custody.

When courts credit the alienation claim, rates of maternal losses of custody increase more drastically:

Mothers' Custody Losses When Courts Credit Fathers' Alienation Claims

Type of Abuse Alleged

Mother Lost Custody

DV:

CPA:

$60 \%(15 / 25)$

CSA:

$59 \%(10 / 17)$

DVCh:

$68 \%(13 / 19)$

CACSA:

$79 \%(19 / 24)$

Any:

$100 \%(6 / 6)$

$73 \%(60 / 82)$

Finally, while the numbers are small, the impact of credited alienation is apparent in the finding that it can negate even credited abuse. Even when courts believe a father has abused a mother, if they also believe the mother is alienating, some mothers still lose custody to the abusive fathers: 
Mothers' Custody Losses When She is Found to be Alienating and He is Found to be an Abuser

Type of Credited Abuse

DV:

CPA:

CSA:

DVCh:

CACSA:

Avg:

\author{
Mother Lost Custody \\ $29 \%(2 / 7)$ \\ $0 \%$ (no cases where abuse $\&$ alienation were both credited) \\ $0 \%($ \\ $57 \%(4 / 7)$ \\ $0 \%$ (no cases where both were credited) \\ $43 \%(6 / 14)$
}

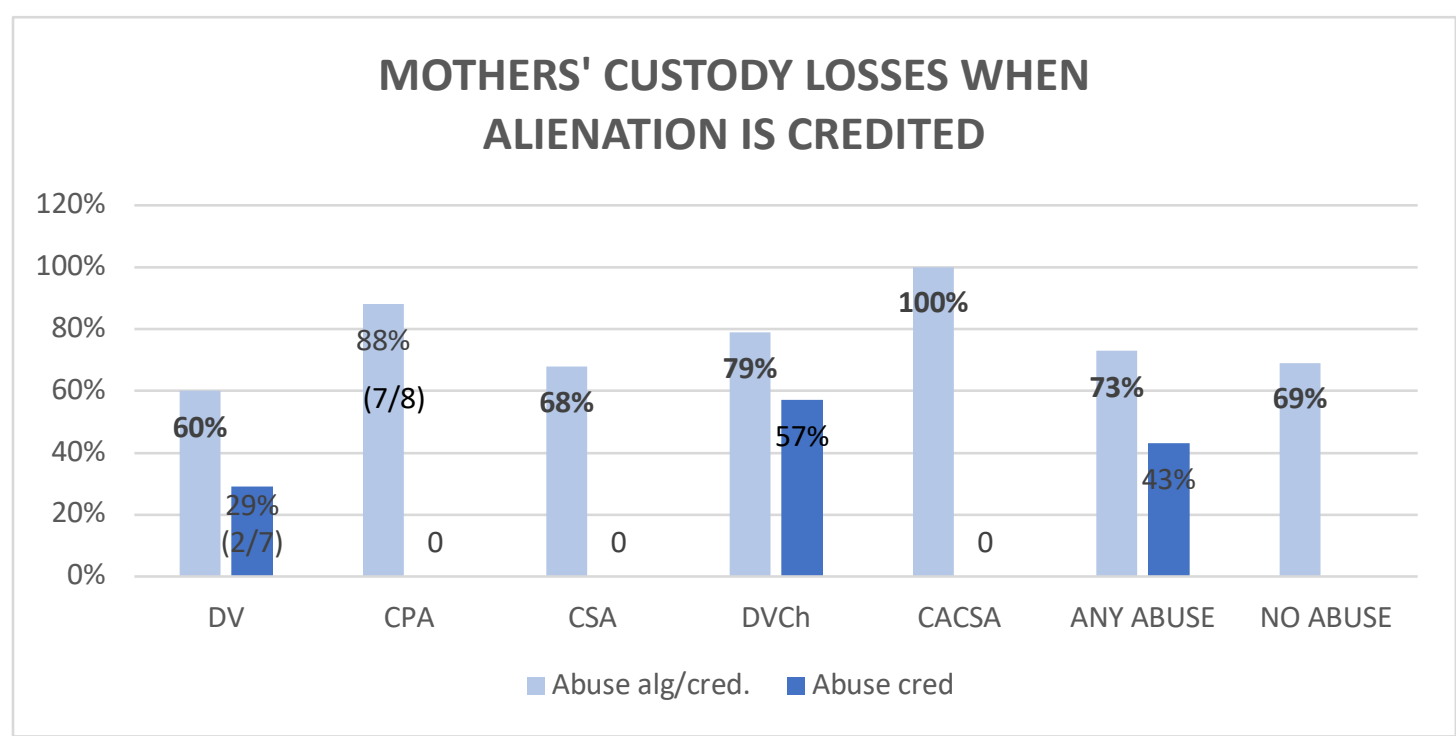

As is indicated by the zeros for credited child physical or sexual abuse, no courts were prepared to believe that both a father's child abuse and a mother's alienation were true. That alienation and child abuse are a "zero sum game" in the eyes of the courts is consistent with the original PAS theory - which framed alienation as using false child abuse claims to undercut father's parenting rights. It is, however, not how modern "alienation theory" is described in the literature. ${ }^{20}$

\section{CUSTODY LOSSES IN AKA CASES}

To expand the relatively small numbers in Section (2)(B) above, we add here a brief discussion of the "AKA" cases: those in which a court viewed a mother as alienating in her behavior but did not use the term "alienation." 21

\footnotetext{
${ }^{20}$ See e.g., Johnston \& Kelly, supra note 17.

${ }^{21}$ Cases were coded "AKA" only when courts expressly found a mother to have engaged in an alienating-type behavior. Mere allegations are not included.
} 


\section{Mothers' Custody Losses when Found to have Committed AKA}

$\begin{array}{lll}\text { Custody Losses by Type of Abuse Alleged } & \begin{array}{l}\text { Custody Losses When } \\ \text { Abuse was Proven }\end{array} \\ \text { DV } & 62 \%(24 / 39) & 60 \%(3 / 5) \\ \text { CPA } & 61 \%(17 / 28) & 50 \%(1 / 2) \\ \text { CSA } & 58 \%(25 / 43) & - \\ \text { DVCh } & 55 \%(16 / 29) & - \\ \text { CACSA } & 78 \%(7 / 9) & 100 \%(1 / 1) \\ \text { Any } & 60 \%(89 / 148) & 63 \%(5 / 8)\end{array}$

These data show that courts' application of alienation-type thinking (that a mother has interfered with the father's rights) without the alienation label, results in similarly high - but not quite as high - rates of custody losses for mothers: Mothers found to be alienators lost custody $\mathbf{7 3} \%$ of the time; those found to have committed something similar (AKA) lost custody $\mathbf{6 0} \%$ of the time. This indicates that when mothers are found to be alienators they have 1.8 times the odds of losing custody compared to when they are judged to have committed similar behavior without the "alienation" label. Thus, while the alienation label is a bit more harmful to mothers, the negative impact of being found to have committed something similar is also great. Among cases where mothers succeeded in proving abuse, while the numbers are too small to hold power, the fact that $63 \%$ of these "AKA" mothers also lost custody shows that not only the alienation label, but simply being perceived as undermining a father's parenting rights, can also trump even proven abuse by a father.

\section{(3) SELECTED GENDER COMPARISONS 22}

We have not completed all the data analyses of the relatively small numbers of gender-reversed cases, but some interesting comparisons are provided here.

\section{Gender differences are particularly notable within the alienation dataset:}

First, fathers' and mothers' rates of custody losses differ significantly when one or the other alleges alienation: Across all alienation cases (with and without abuse claims), when fathers alleged mothers were alienators they took custody from her $44 \%$ of the time $(166 / 380)$. When the genders were reversed, mothers took custody from fathers only $28 \%$ of the time (19/67). This means that when either parent is accused of alienation, mothers have twice the odds of losing custody compared to fathers in cases with alienation claims.

22 More robust gender analyses are available in the "All Abuse" dataset described in (5), below. 
Second, within the cases where one party alleged abuse and the other defended with alienation, mothers accused of alienation lost custody to the fathers they accused of abuse $50 \%(81 / 163)$ of the time, fathers who were accused of alienation by the mother they accused of abuse lost custody only $29 \%(5 / 17)$ of the time. ${ }^{23}$

\section{There are also some interesting gender parities:}

First, when a parent's claim of alienation is credited (across abuse and nonabuse cases), the genders fare equally: Both mothers and fathers lose custody at identical rates when the court deems them an alienator (71\%). Surprisingly, this parity does not carry over to the "AKA" cases, i.e., those where courts found one parent had committed alienation-like behaviors: Where mothers were found to have committed AKA, 63\% (155/246) lost custody; where fathers were found to have committed $A K A$, only $47 \%$ (9/19) lost custody.

Second, "win" 24 rates are identical (89\%) for mothers and fathers when the other parent is found to have committed alienation. Win rates are also very close when one parent alleges alienation in the non-abuse cases ( F 58\%, M $56 \%$ ). This parity shrinks ${ }^{25}$, however, when abuse and alienation are both alleged (fathers win 66\%; mothers 52\%)

Comment on gender differences and parities: The gender parities in alienation cases without abuse claims suggest a nuanced, compelling, and "something-for-everyone" potential explanation of the highly contested matter of how alienation operates in custody litigation. First, the presence in this dataset of more alienation cases without abuse claims (357) than with abuse claims (312), as well as the apparent gender neutrality in courts' handling of these non-abuse cases supports the assertions of some alienation specialists that alienation claims are not intrinsically gender-biased and that alienation should not be considered simply a strategy for denying abuse claims. At the same time, however, the contrast between these non-abuse cases and the gendered outcomes in cases where alienation and abuse are cross-claimed, supports the complaints of protective mothers who have sought to prove a father was abusive but were defeated by alienation claims which seemed to negate any validity to the abuse, especially when the alienation was credited. That the same dynamic does not appear in abuse/alienation cases when the genders are reversed, i.e., fathers do not see a statistically significant lower rate of crediting of their abuse claims when mothers cross-claim alienation, suggests that alienation in abuse cases continues to be deeply gendered and, in fact, continues to be used effectively to deny mothers' abuse claims.

${ }^{23}$ This difference is not statistically significant.

${ }^{24}$ Winning is defined as the parent who "substantially won," i.e., received all or part of their own custody/visitation request or defeated the other parent's request. DOCUMENTATION Appendix B (Coding Manual) at 7.

${ }^{25}$ The difference is not statistically significant at the .05 level, but it is at the 0.1 level. 
This dataset consists of all 2794 cases where abuse by one parent was alleged, both intrafamilial and extrafamilial, including both alienation and AKA cases. It also includes cases that were excluded from the analytic database because they did not identify a specific type of abuse; here in the "All Abuse" dataset we categorized these as either adult or child physical abuse. We chose to analyze this expanded dataset both to enlarge some data cells, especially in the reverse-gender cases, and because we deem it important to be able to make generalizations about what happens in custody litigation where abuse is alleged in general, without necessarily knowing whether cases involve alienation claims or not.

With this larger dataset, we were able to include consideration of corroboration, and the impact of GALs and Evaluators on crediting of abuse and custody losses.

Two interesting general findings indicate that among all abuse cases, fathers win more than mothers ( $50 \% \vee 47 \%)$, and that mothers lose custody more than fathers $(32 \% \vee 22 \%)$.

\section{CREDITING OF MOTHERS' ABUSE CLAIMS against FATHERS}

\section{A. In general}

\section{When mothers report abuse by fathers, courts credit abuse claims at the following rates:}

$\begin{array}{ll}\text { DV: } & 43 \%(459 / 1077) \\ \text { CPA: } & 21 \%(71 / 341) \\ \text { CSA: } & 19 \%(59 / 304) \\ \text { DVCh: } & 48 \%(197 / 413) \\ \text { CACSA: } & 16 \%(9 / 55) \\ \text { Any: } & 36 \%(795 / 2189)\end{array}$

Comment: On average this dataset indicates a lower rate of crediting (36\%) than the abuse-no-alienation analytic dataset (41\%); this makes sense since this fuller dataset includes alienation cases where rates of crediting are even lower (26\%).

As with the Analytic Dataset, these data demonstrate that courts are much less likely to credit mothers' claims of child abuse than domestic violence: They are 2.8 times less likely to credit child physical abuse and 3.1 times less likely to credit child sexual abuse - than domestic violence. 


\section{B. Crediting of Mothers' Claims of Abuse - Corroboration}

Corroboration was coded for a filed or granted protection order, an arrest, or a prosecution for interpersonal violence or abuse. ${ }^{26}$ Thus, for example, a claim of child abuse was coded as "corroborated" if there was a CPO or arrest or prosecution for adult domestic violence or assaults on other individuals, as well as for child abuse.

\section{Crediting of M's abuse claims when corroboration}

$\begin{array}{ll}\text { DV: } & 36 \%(123 / 340) \\ \text { CPA: } & 23 \%(9 / 40) \\ \text { CSA: } & 19 \%(10 / 53) \\ \text { DVCh: } & 45 \%(71 / 159) \\ \text { CACSA: } & 0 \%(0 / 7) \\ \text { Any: } & 36 \%(213 / 599)\end{array}$

\section{Crediting of M's abuse claims when no corroboration}

$\begin{array}{ll}\text { DV: } & 33 \%(202 / 603) \\ \text { CPA: } & 19 \%(56 / 295) \\ \text { CSA: } & 10 \%(22 / 224) \\ \text { DVCh: } & 36 \%(71 / 199) \\ \text { CACSA: } & 11 \%(5 / 44) \\ \text { Any: } & 26 \%(356 / 1364)\end{array}$

Comment: As would be expected, when comparing cases with no corroboration to cases with corroboration, rates of crediting increase slightly, except among the mixed CACSA category, though this difference is not statistically significant. While rates of crediting are still quite low in general, some form of corroboration increases the likelihood of crediting of mothers' abuse claims by 1.56 (2.68 for any type of child abuse).

\section{Crediting of Mothers' Claims of Abuse - GALs}

Protective parents and their attorneys have claimed that GALs fail to recognize abuse - especially child abuse - or the risk of such abuse. The data are consistent with this critique in that they indicate that the presence of a GAL reduces the rates at which courts credit mothers' abuse claims.

\section{Crediting of M's abuse claims When No GAL}

$\begin{array}{ll}\text { DV } & 44 \%(340 / 779) \\ \text { CPA } & 23 \%(50 / 218) \\ \text { CSA } & 21 \%(38 / 181) \\ \text { DVCh } & 47 \%(131 / 278) \\ \text { CACSA } & 20 \%(6 / 30)\end{array}$

\section{Crediting of M's abuse claims when GAL Present}

$$
\begin{aligned}
& 40 \%(119 / 298) \\
& 17 \%(21 / 123) \\
& 17 \%(21 / 123)^{27} \\
& 49 \% 66 / 135) \\
& 12 \%(3 / 25)
\end{aligned}
$$

\footnotetext{
${ }^{26}$ DOCUMENTATION, Appendix B(Coding Manual) at 15-16. Where there was a criminal conviction we coded the abuse as "credited", so those are not included in this analysis. 27 The surprising identical numbers in the CPA and CSA categories here were doublechecked and are correct.
} 
Overall, abuse is 1.26 times more likely to be credited without a GAL than with one $(38 \% \vee 33 \%)$. In contrast, data not included here show that the presence of a GAL has no material impact on the crediting of abuse when alleged by fathers against mothers $(32 \% \vee 31 \%)$.

\section{Crediting of Mothers' Claims of Abuse - Evaluators}

The study coded the presence of court-appointed neutral custody evaluators. ${ }^{28}$ Anecdotal complaints and research have reported that many custody evaluators fail to recognize abuse or its implications for safety of the children. The data provide support for this critique.

\section{Crediting of M's Abuse Claims When No Evaluator}

$\begin{array}{ll}\text { DV } & 44 \%(372 / 853) \\ \text { CPA } & 22 \%(57 / 256) \\ \text { CSA } & 23 \%(47 / 207) \\ \text { DVCh } & 50 \%(139 / 277) \\ \text { CACSA } & 28 \%(9 / 32) \\ \text { ANY } & 38 \%(624 / 1624)\end{array}$

\section{Crediting of M's Abuse Claims When Evaluator Present}

$$
\begin{aligned}
& 39 \%(87 / 224) \\
& 16 \%(14 / 85) \\
& 12 \%(12 / 97) \\
& 43 \%(58 / 136) \\
& 0.4 \%(1 / 23) \\
& 30 \%(171 / 565)
\end{aligned}
$$

These data indicate that mothers reporting abuse by a father do not benefit when there is a court-appointed evaluator in the case. Abuse is 1.44 times more likely to be credited by the court if there is no evaluator ( $38 \% \vee 30 \%$ ). The difference is particularly strong when it comes to child sexual abuse, which is half as likely to be credited (reduced from an already low rate) if there is an evaluator in the case. Future publications will discuss the reality that most neutral custody evaluators lack expertise in child sexual abuse, indicating that their skepticism is not a product of greater knowledge.

Gender: Again, as with GALs, the impact of Evaluators on mothers' credibility stands in contrast to the virtually complete lack of impact of an evaluator's presence on the crediting of fathers' claims of abuse against mothers (33\% v $32 \%)$.

${ }^{28}$ See Coding Manual at 22-23. 


\section{LOSS OF CUSTODY - Gender Comparisons}

There were 1353 cases in which mothers started with physical possession of the children, and alleged some type of abuse by the father in the custody litigation. In this all-abuse dataset, they lost custody a bit more often but close to the rates found in the analytic dataset in cases without alienation defenses (approximately $25 \%$ ). There were 127 cases in which fathers started with physical possession of the children, and alleged abuse by the mother.

\section{A. Custody Switches Overall}

\section{Mothers' Custody Losses when Alleging Abuse}

$\begin{array}{ll}\text { DV: } & 22 \%(146 / 656) \\ \text { CPA: } & 34 \%(62 / 185) \\ \text { CSA: } & 32 \%(68 / 211) \\ \text { DVCh: } & 32 \%(89 / 276) \\ \text { CACSA: } & 56 \%(20 / 36) \\ \text { Any: } & 28 \%(384 / 1353)\end{array}$

\section{Fathers' Custody Losses when Alleging Abuse}

$\begin{array}{ll}\text { DV: } & 14 \%(6 / 43) \\ \text { CPA: } & 11 \%(7 / 65) \\ \text { CSA: } & 33 \%(2 / 6) \\ \text { DVCh: } & 0 \%(0 / 12) \\ \text { CACSA: } & 0 \%(0 / 1) \\ \text { Any: } & 12 \%(15 / 127)\end{array}$

Here, as in the analytic dataset, mothers who report abuse in custody litigation face significant risks of losing custody to the alleged abuser, ranging from $22 \%$ to $56 \%$. As also seen earlier, mothers' risks of losing custody are significantly higher when they allege child abuse than when they allege adult abuse: When a mother alleges any type of child abuse she is 1.8 times more likely to lose custody than when she alleges DV; when she alleges mixed physical and sexual child abuse, her odds of losing custody increase to 4.4 times higher than when she alleges DV.

The gender contrast here is also stark: Mothers are nearly 3 (2.9) times more likely than fathers to lose custody when alleging abuse by the other parent; when they allege child abuse their odds of losing custody increase to 4.2 times more than fathers'.

\section{B. Custody Switches to Proven Abuser}

Mothers' Custody Losses Despite Proven F Abuse

$\begin{array}{ll}\text { DV: } & 12 \%(35 / 285) \\ \text { CPA: } & 24 \%(8 / 34) \\ \text { CSA: } & 2 \%(1 / 46)\end{array}$

Father's Custody Losses Despite Proven M Abuse

$\begin{array}{ll}\text { DV: } & 10 \%(2 / 20) \\ \text { CPA: } & 0 \%(0 / 23) \\ \text { CSA: } & 0 \%(0 / 1)\end{array}$ 


$\begin{array}{llll}\text { DVCh: } & 14 \%(19 / 133) & \text { DVCh: } & 0 \%(0 / 6) \\ \text { CACSA: } & 17 \%(1 / 6) & \text { CACSA: } & 0 \%(0 / 1) \\ \text { Any: } & 13 \%(64 / 505) & \text { Any: } & 4 \%(2 / 51)\end{array}$

Perhaps the most notable entry here is the comparison between fathers and mothers who prove the other parent committed child physical abuse. While fathers who are proven to have committed child physical abuse still take custody from the mother $24 \%$ of the time, mothers proven to be child abusive never received custody. While it is surprising that any parent proven to have committed child abuse would receive custody, it is possible to conceive of facts that could justify this; however, the 0 under fathers' custody losses reflects the more logical, yet apparently gender-biased reality.

\section{Custody Switches - GALs}

Mothers' Custody Losses - With GAL

$\begin{array}{ll}\text { DV } & 28 \%(50 / 180) \\ \text { CPA } & 51 \%(35 / 69) \\ \text { CSA } & 36 \%(30 / 83) \\ \text { DVCh } & 37 \%(34 / 92) \\ \text { CACSA } & 79 \%(11 / 14) \\ \text { Any } & 36 \%(159 / 437)\end{array}$

Fathers' Custody Losses - GALs

$\begin{array}{lll}\text { DV } & 8 \% & (1 / 12) \\ \text { CPA } & 13 \% & (3 / 24) \\ \text { CSA } & 0 \% & (0 / 2) \\ \text { DVCh } & 0 \% & (0 / 4) \\ \text { CACSA } & - & - \\ \text { Any } & 10 \% & (4 / 42)\end{array}$

Without GAL

$\begin{array}{ll}\text { DV } & 21 \%(96 / 466) \\ \text { CPA } & 23 \%(27 / 116) \\ \text { CSA } & 30 \%(38 / 128) \\ \text { DVCh } & 30 \%(55 / 184) \\ \text { CACSA } & 41 \%(9 / 22) \\ \text { Any } & 25 \%(225 / 916)\end{array}$

As in the analytic dataset, GALs hurt protective mothers' cases: Mothers are 1.76 times more likely to lose custody when a GAL is present, increasing to 3.4 times when alleging physical child abuse and $\mathbf{5 . 3}$ times when alleging mixed physical and sexual child abuse.

In contrast, GALs have no significant impact on protective fathers' likelihood of losing custody. The net effect is that GALs greatly intensify gender differences in these cases: Without a GAL a mother alleging any abuse is 2.2 times more likely to lose custody than a father; with a GAL, that same mother is $\mathbf{5 . 4}$ times more likely than a father to lose custody. When alleging 
any type of child abuse, without a GAL, mothers are 3.2 times as likely to lose custody as fathers; with a GAL those odds increase to 6.6.

\section{Custody Switches - Evaluators}

\section{Mothers' Custody Losses - with Evaluator Without Evaluator}

$\begin{array}{llll}\text { DV } & 34 \%(47 / 140) & \text { DV } & 20 \%(99 / 506) \\ \text { CPA } & 52 \%(26 / 50) & \text { CPA } & 27 \%(36 / 135) \\ \text { CSA } & 48 \%(35 / 73) & \text { CSA } & 24 \%(33 / 138) \\ \text { DVCh } & 40 \%(40 / 99) & \text { DVCh } & 28 \%(49 / 177) \\ \text { CACSA } & 80 \%(12 / 15) & \text { CACSA } & 38 \%(8 / 21) \\ \text { Any } & 42 \%(160 / 377) & \text { Any } & 23 \%(224 / 976)\end{array}$

Mothers are 2.48 times more likely to lose custody when an evaluator is present than not, increasing to nearly 3 (2.98) times more likely when alleging physical child abuse, and $\mathbf{6 . 5}$ times more likely when alleging both physical and sexual child abuse.

Fathers' Custody Losses - with Evaluator

$\begin{array}{ll}\text { DV } & 25 \%(2 / 8) \\ \text { CPA } & 14 \%(2 / 14) \\ \text { CSA } & 50 \%(1 / 2) \\ \text { DVCh } & 0 \%(0 / 6) \\ \text { CACSA } & - \\ \text { Any } & 17 \%(5 / 30)\end{array}$

Without Evaluator

$\begin{array}{lll}\text { DV } & 11 \% & (4 / 35) \\ \text { CPA } & 10 \% & (5 / 51) \\ \text { CSA } & 25 \% & (1 / 4) \\ \text { DVCh } & 0 \% & (0 / 6) \\ \text { CACSA } & 0 \% & (0 / 1) \\ \text { Any } & 10 \% & (10 / 97)\end{array}$

These data indicate that the presence of an evaluator has no statistically significant effect on protective fathers' custody losses. (While the fathers' custody losses are more "frequent" with evaluators, the frequencies lack power given the very small numbers.)

Thus, the presence of evaluators also exacerbates the gender difference in custody cases where a parent alleges abuse: When there is no evaluator, a mother alleging abuse is 2.6 times as likely to lose custody as a father; with an evaluator, they are 3.7 times as likely to lose custody. When alleging physical child abuse, mothers are 3.3 times as likely to lose custody as fathers when there is no evaluator; when there is an evaluator, mothers their odds of losing custody are 6.5 times higher than fathers'. 


\section{Brief Summary of Findings}

The core findings from this study provide strong support for the critiques of family courts' handling of cases involving mothers' claims of abuse by fathers. The data show that courts are excessively skeptical of child physical and sexual abuse reports, are likely overly skeptical of domestic violence claims, and sometimes award custody to known abusers. Overall, mothers reporting abuse - particularly child abuse - are losing custody at high rates.

The data also support the critiques of parental alienation theory as it is used in custody litigation. Alienation virtually doubles the rates of mothers' custody losses while halving the rate at which mothers' abuse claims are believed. It operates powerfully as a defense for fathers accused of abuse, but not mothers accused of abuse.

Finally, the data also support protective parents' critiques of GALs and custody evaluators - these purportedly neutral professionals tend to benefit fathers accused of abuse, and increase rates of mothers' custody losses to such fathers.

\section{Policy Implications}

These findings warrant action in several domains.

\section{Education of Court Professionals}

Many family court judges and affiliated/appointed professionals see themselves as neutral, while entertaining a general skepticism toward women alleging abuse. The study's data indicated that there is widespread gender bias in courts' handling of these abuse claims. They also indicate that child abuse claims are extensively under-validated, putting children at great risk. Courts and affiliated professionals should therefore be educated about these data and encouraged to 
challenge their own and others' implicit biases, through mandated and voluntary trainings. In addition, such professionals should be required to participate in training on child physical and sexual abuse, to refute common misconceptions that are used to deny such claims. Alienation theory plays a significant role in the denial of child abuse reports. This study should be used to deconstruct those misconceptions and develop new and mandated trainings to return courts to their most important mission: protecting at-risk children.

Family courts continue to rely on parental alienation theory in large part because it is endorsed by respected, mental health professionals considered leaders in the field. Workshops and conferences sponsored by the Association of Family and Conciliation Courts, and attended by family court professionals from around the nation and around the world, include training sessions on parental alienation. Such professionals must be educated on the biased application of that theory where abuse is concerned. The results of this study should be included in seminars and training materials for judges and all court professionals who deal with custody of children.

\section{Child Welfare Professionals}

Child welfare agencies also regularly discredit child abuse claims when raised by a mother in custody litigation, often based on alienation theory. It is critical for social service professionals who deal with child maltreatment to be educated on the biases implicit in alienation theory and its application to parents in custody litigation. The federal government can legislate the terms on which state child welfare agencies operate through federal funding streams authorized by the Child Abuse Prevention and Treatment Act (CAPTA). Therefore, Congress should consider 
amending CAPTA to prohibit child welfare agencies from applying alienation theory in assessing child maltreatment reports, and to require education about these data and the scientific and logical flaws in alienation theory.

\section{Lawyers}

Lawyers handling cases at trial for survivors of abuse and protective parents need to be aware of these data to prevent or prepare for unfavorable outcomes. They may want to consider presenting some of the findings from this study to educate judges who are weighing the opinions of GALs and evaluators and are themselves trying to adjudicate hotly contested claims of abuse and alienation. Lawyers in appeals of such cases should consider citing these data in their appellate briefs, and especially, briefs of amici curiae. Lawyers may need to frame these data expressly in terms of gender bias in order to obtain serious review by courts.

\section{Federal and State Legislation}

The study findings lend themselves to myriad legislative changes. State legislators should consider excluding or constraining the use of parental alienation in custody cases where abuse is alleged. They should consider requiring judges and any other appointed neutral professionals to complete expert training on child physical and sexual abuse, including the ways alienation theory is improperly used to deny abuse and to fuel misconceptions about how abused children and abusing parents behave. They should consider adopting requirements for such training and a minimal degree of expertise in child abuse and domestic violence before an individual may be appointed as a neutral professional in a custody case.

The U.S. House of Representatives has already passed H.Con.Res.72, stating that child safety should be the primary concern of family courts in making custody 
decisions. The Resolution urges state courts and policymakers to ensure that only valid scientific evidence is considered in family courts and that abuse/danger claims are resolved before considering other "best interest" factors (such as "friendly parent" or alienation-type considerations). This Resolution can and should be used in state legislatures to push more protective statutes such as those described above.

\section{Review and Modifications to government-funded programs}

A number of Access and Visitation (AV) programs funded by the Office of Child Support Enforcement of the Department of Health and Human Services have drawn on parental alienation theory. For example, AV contracts obtained from certain grantees in the State of Texas listed parental alienation as one of the services allowed by the AV program, and claimed that that parental alienation theory was endorsed by the enabling federal legislation. That language was ultimately removed after it was brought to the attention of a program manager, and discovered that the legislation had been distorted.

Another program (in Arizona) permitted courts to require parents who failed to comply with court-ordered visitation to attend a four-hour class on parental alienation (sometimes under other names). ${ }^{29}$ Another common program required by courts and sometimes funded by federal agencies may involve "reunification counseling," a method spawned by alienation theory, which has been subject of even greater critique.

\footnotetext{
29 Jessica Pearson \& David Price, Access and Visitation Programs: Promising Practices, Department of Health and Human Services, Administration for Children and Families, Office of Child Support Enforcement, 2004, pii, and p. 64.
} 
Other federally funded fatherhood programs also use a variety of terms ("AKAs") for parental alienation, in particular "gate-keeping." For instance, recently, a federally-funded evaluation of fatherhood programs mentioned abuse as a possible reason for "gate-keeping," but did not ask survey respondents whether abuse had been a factor, despite the fact that $95 \%$ of them had had contact with the criminal justice system. The report also echoed the fathers' claims that the mothers had made false domestic violence claims against them. Consistent with what we see in courts, in this context again we see alienation theory being taken for granted and fathers treated as victims. The study recommends more legal services for noncustodial fathers to establish parenting time agreements. ${ }^{30}$

It is therefore important for OCSE and other federal agencies to educate federally funded programs about both the lack of scientific evidence supporting the alienation theory and the findings of this study regarding its deleterious effect on child safety. The federal government should establish clear policies prohibiting funding of services by or referrals to providers guided such theories. And federallyfunded program evaluations should be mandated to explore whether abuse is an underlying reason why a mother may resist a father's access to their children.

\footnotetext{
30 Pamela Holcomb et al., In Their Own Voices; The Hopes and Struggles of Responsible Fatherhood Program Participants in the Parents and Children Together Evaluation, OPRE Report 2015, Mathematica Policy Research, June, 2015, and p. 46, available at https://www.acf.hhs.gov/sites/default/files/opre/pact qualitative report 6172015 b508 3.pdf. While acknowledging that domestic violence and child maltreatment can be legitimate reasons for "gate-keeping," the Report nonetheless identifies that as the overarching problem and reason why such fathers need more lawyers.
} 